\title{
Hypoxia Stimulates the Epithelial-to-Mesenchymal Transition in Lung Cancer Cells Through Accumulation of Nuclear $\beta$-Catenin
}

\author{
KAO-HUI LIU ${ }^{1,2}$, YI-TA TSAI ${ }^{2}$, SZU-YING CHIN ${ }^{1}$, WOAN-RUOH LEE ${ }^{1,2,3}$, \\ YEN-CHOU CHEN ${ }^{2,4,5}$ and SHING-CHUAN SHEN ${ }^{2,3,4}$ \\ ${ }^{1}$ Department of Dermatology, Taipei Medical University Shuang Ho Hospital, New Taipei City, Taiwan, R.O.C.; \\ ${ }^{2}$ Graduate Institute of Medical Sciences, College of Medicine, Taipei Medical University, Taipei, Taiwan, R.O.C.; \\ ${ }^{3}$ Department of Dermatology, School of Medicine, College of Medicine, \\ Taipei Medical University, Taipei, Taiwan, R.O.C.; \\ ${ }^{4}$ International Master/PhD Program in Medicine, College of Medicine, \\ Taipei Medical University, Taipei, Taiwan, R.O.C.; \\ ${ }^{5}$ Cancer Research Center and Orthopedics Research Center, \\ Taipei Medical University Hospital, Taipei, Taiwan, R.O.C.
}

\begin{abstract}
Background/Aim: Recent studies implied a significant role of hypoxia-inducible factor-1 $\alpha$ (HIF $1 \alpha)$ in cell transformation. This study aimed to assess the effects of HIF $1 \alpha$ on the epithelial-to-mesenchymal transition (EMT) and tumorigenesis of lung adenocarcinoma cells. Materials and Methods: Invasion, migration and colony formation assays were used to evaluate cell transformation. Expression of EMT-related markers were analyzed by western blot, reverse-transcription polymerase chain reaction or zymography. A luciferase assay was carried out to access the transcriptional activity of $\beta$-catenin. Results: Hypoxia enhanced migration, invasion and transformation of A549 lung adenocarcinoma cells. Hypoxic stimulation promoted the expression of EMT-related markers in lung cancer cells. The expression of HIFla was found to be involved in hypoxia-mediated modulation of expression of snail family transcriptional repressors 1 (SNAII) and 2 (SLUG). Hypoxia enhanced nuclear accumulation and transcriptional activity of $\beta$-catenin. Conclusion: $\beta$-Catenin promotes expression of EMT-related genes and eventually contributes to the metastatic process.
\end{abstract}

Lung cancer is a leading cause of cancer deaths and the second most common cancer in the United States $(1,2)$. The cancer survival rate has improved over the past few decades; however, the improvement is mainly due to early

Correspondence to: Shing-Chuan Shen, 250 Wuxing St., Taipei 11031, Taiwan, ROC. E-mail: scshen@tmu.edu.tw

Key Words: Lung cancer, hypoxia, epithelial-to-mesenchymal transition, EMT, $\beta$-catenin. detection and cancer growth inhibition (3). Cancer metastasis is one of the major causes for poor prognoses of patients with lung cancer. The nervous system, bone, and liver are the most frequent metastatic sites for lung cancer. A previous population-based study indicated that the median survival after diagnosis was 13 months for those with nonmetastatic lung cancer and 5 months for those with metastatic lung cancer (4). However, the mechanism of lung cancer metastasis has not been fully elucidated. A lack of understanding of the metastatic mechanisms and process has limited the prevention and inhibition of lung cancer metastasis.

Hypoxia is a feature of most solid tumors (5). One major reason for tumor hypoxia is the formation of insufficient and abnormal vessels in tumor tissues (6). Mechanisms of the tumor cell response to hypoxia are mainly mediated by hypoxia-inducible factor- $1 \alpha(\mathrm{HIF} 1 \alpha)$, which promotes tumor cell adaptation to a hypoxic environment and potentiates tumor malignancy. Previous studies implied that intratumoral hypoxia and the epithelial-to-mesenchymal transition (EMT) play crucial roles in the progression and aggressiveness of many types of cancer (7-9). For solid tumors, the EMT is known as a critical mechanism in migration and invasion. Recent studies showed that HIF1 $\alpha$ plays a significant role in cell transformation, in which a tumor comprising mostly the sedentary epithelial type of cells changed into a tumor with invasive and metastatic fibroblastic types of cells (7). Several transcriptional repressors (Twist-related protein (TWIST), snail family transcriptional repressors 1 (SNAI1), and 2 (SLUG) are important in regulating the EMT by suppressing several epithelial markers and adhesion molecules, including E-cadherin, in breast and ovarian cancer (10-12). 
Table I. Primers used for the reverse-transcription polymerase chain reaction.

\begin{tabular}{llll}
\hline Gene & Encoded protein & Forward primer & Reverse primer \\
\hline COL1A1 & Collagen type I & ACGTCCTGGTGAAGTTGGTC & ACCAGGGAAGCCTCTCTCTC \\
$F N 1$ & Fibronectin & CCGTGGGCAACTCTGTC & TGCGGCAGTTGTCACAG \\
SLUG & Snail family transcriptional repressor 2 & AGCTACCCAATGGCCTCTCT & CCAGCCCAGAAAAAGTTGAA \\
SNAI1 & Snail family transcriptional repressor 1 & GCCTTCAACTGCAAATACTGC & CTTCTTGACATCTGAGTGGGTC \\
SIP1 & SMAD interacting protein 1 & AAAACCATGGCGTGGGTA & CAATAGCCGAGGCATCAAC \\
TWIST & TWIST & AGCTACGCCTTCTCGGTCT & CCTTCTCTGGAAACAATGACATC \\
ZEB1 & Zinc finger E-box binding homeobox 1 & ACTGCTGGGAGGATGACAGA & ATCCTGCTTCATCTGCCTGA \\
GAPDH & Glyceraldehyde-3-phosphate dehydrogenase & AGCCACATCGCTCAGACAC & GCCCAATACGACCAAATCC \\
\hline
\end{tabular}

Targeting hypoxic cells is one pharmacological approach for managing solid tumors (13). Several studies aimed to develop new medications that block hypoxic tumor cells and their underlying progression $(13,14)$. Based on clarification of the mechanisms of hypoxia-induced EMT, it is possible to develop new therapeutic strategies to manage lung cancer metastasis.

Recently, several studies investigated hypoxia-induced EMT in cancer cells $(7,15,16)$; however, details of the underlying mechanism remain unclear. To find new therapeutic medications which target hypoxia-induced lung cancer metastasis, this study investigated mechanisms involved in hypoxia-induced EMT in lung cancer cells.

\section{Materials and Methods}

Cell culture. The human alveolar adenocarcinoma A549 cell line (BCRC, Hsinchu, Taiwan, ROC) was cultured in Dulbecco's modified Eagle medium (DMEM; Gibco, Carlsbad, CA, USA) supplemented with $10 \%$ heat-inactivated fetal bovine serum (FBS; Gibco) and with $1 \%$ L-glutamine. Cells were incubated in a $37^{\circ} \mathrm{C}$ humidified culture incubator with $5 \% \mathrm{CO}_{2}$.

Induction of hypoxia. A hypoxic condition was created either by chemical induction or by using a hypoxic environment. For chemical induction, $100 \mu \mathrm{M}$ cobalt chloride (Sigma, St. Louis, MO, USA) was used as the chemical hypoxia-mimetic agent, which was added to cultured cells for 24,48 , and $72 \mathrm{~h}$. To induce hypoxia, cells were placed in a hypoxic chamber with an oxygen concentration maintained at $1 \% \mathrm{O}_{2}$.

Transfection. The cell line was transfected using Lipofectamine 2000 (Invitrogen, Carlsbad, CA, USA) according to the manufacturer's instructions. In brief, $1 \times 10^{6}$ A549 cells were seeded onto $3.5 \mathrm{~cm}$ dishes overnight for cell attachment. Stealth RNA interference (RNAi) for HIF1 $\alpha$ (Invitrogen) or the Stealth RNAi negative control (Invitrogen) was mixed with Lipofectamine and then added to cultured cells for $16 \mathrm{~h}$.

$R N A$ isolation and reverse-transcription polymerase chain reaction $(R T-P C R)$ amplification. RNA from the cells was extracted as previously described (17). Aliquots of $5 \mu \mathrm{g}$ RNA were reverse transcribed with a first-strand complementary (c)DNA synthesis kit (Fermentas, Waltham, MA, USA). cDNA was then used as a template for PCR amplification. The primers used are listed in Table I.

Western blot analysis. Cell protein extraction and preparation, and the western blot analysis were performed as previously described (18). Primary antibodies to the following proteins were used: $\alpha$ smooth muscle actin (SMA), connective tissue growth factor (CTGF), and collagen type I were from Santa Cruz (Dallas, Tx USA); $\beta$-catenin, $\gamma$-catenin, and HIF1 $\alpha$ were from Abcam (Cambridge, MA, USA); E-cadherin and $\mathrm{N}$-cadherin were from Millipore (Carlsbad, CA, USA); fibronectin was from Bioworld (Louis Park, MN, USA); and vimentin was from Novus (Littleton, CO, USA). Generic actin (MD Bio, Taipei, Taiwan, ROC) was used as an internal control. Images were analyzed by Image-Pro Plus software (version 4.5; Media Cybernetics, Rockville, MD, USA).

Wound-healing assay. A549 cells were seeded onto 6-well plates overnight, and then a $200-\mu l$ pipette tip was used to make a straight scratch though the cell layer. Cells were then treated with normoxia $\left(21 \% \mathrm{O}_{2}\right)$, hypoxia $\left(1 \% \mathrm{O}_{2}\right)$, or $100 \mu \mathrm{M}$ cobalt chloride. Changes in wound-healing activity were visualized by microscopy $24 \mathrm{~h}$ after treatment. The relative distance of the wounded area $(\mu \mathrm{m})$ was depicted. Cell motility was quantified by measuring the distance between the invading fronts of cells in three randomly selected microscopic fields. The degree of motility is expressed as wound closure compared to that at the zero-time point.

Soft-agar colony-formation assay. For the soft-agar assay, $1 \mathrm{ml}$ of a $1.4 \%$ agar solution in DMEM containing 10\% FBS was solidified in 6 -well plates. Then, $1 \mathrm{ml}$ of $0.7 \%$ agar solution, mixed with $1 \times 10^{4}$ A549 cells, was layered on top of the base agar layer. Cells were next treated with normoxia $\left(21 \% \mathrm{O}_{2}\right)$, hypoxia $\left(1 \% \mathrm{O}_{2}\right)$, or $100 \mu \mathrm{M}$ cobalt chloride. After incubation for 21 days at $37^{\circ} \mathrm{C}$, colony formation was analyzed and counted under light microscopy.

Transwell assay. In total, $5 \times 10^{4}$ A549 cells in serum-free medium were seeded onto the upper compartment of a transwell chamber (pore size: $8 \mu \mathrm{m}$; Corning ${ }^{\circledR}$ Transwell ${ }^{\circledR}$ Costar $^{\circledR}$, Corning, New York, USA) and allowed to invade into the lower chamber with medium containing 10\% FBS under normoxia or hypoxia for $24 \mathrm{~h}$. Invaded cells were fixed by $10 \%$ formaldehyde and stained with Giemsa solution (Merck, Carlsbad, CA, USA) and then captured under light microscopy. 
A

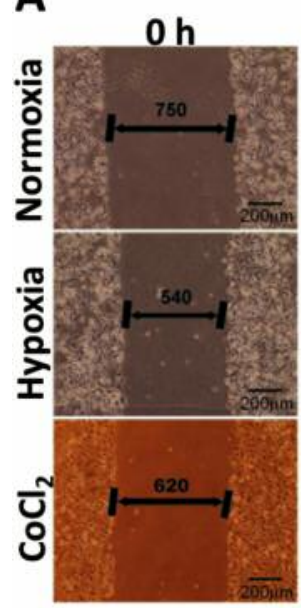

$24 \mathrm{~h}$
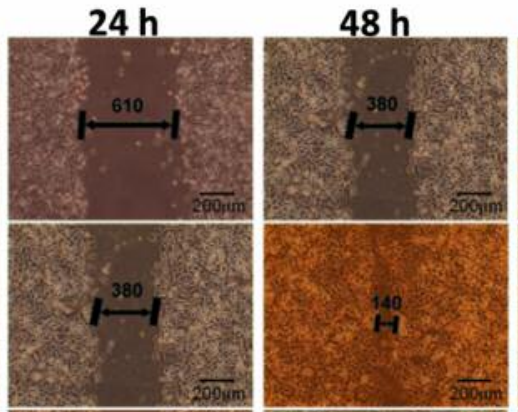

$72 \mathrm{~h}$
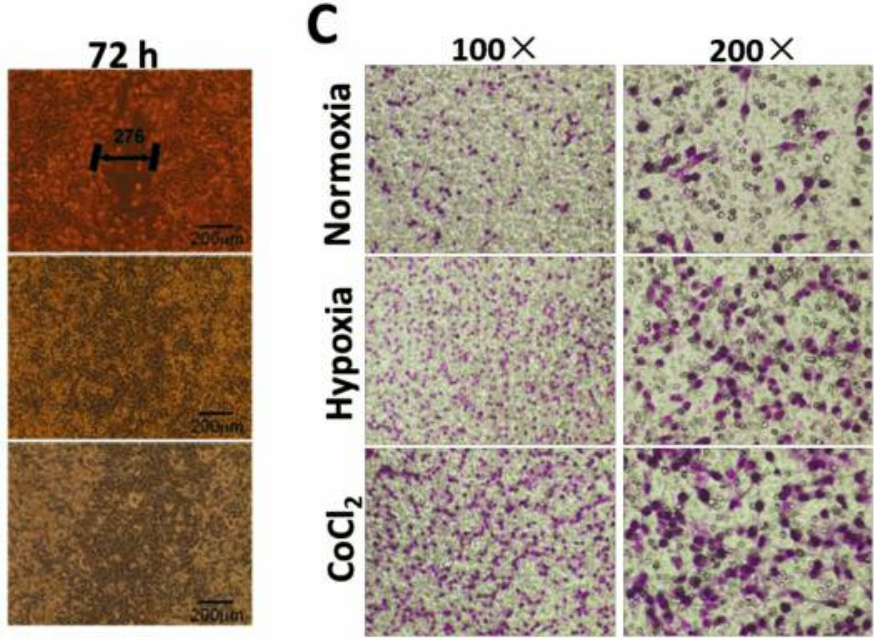

B
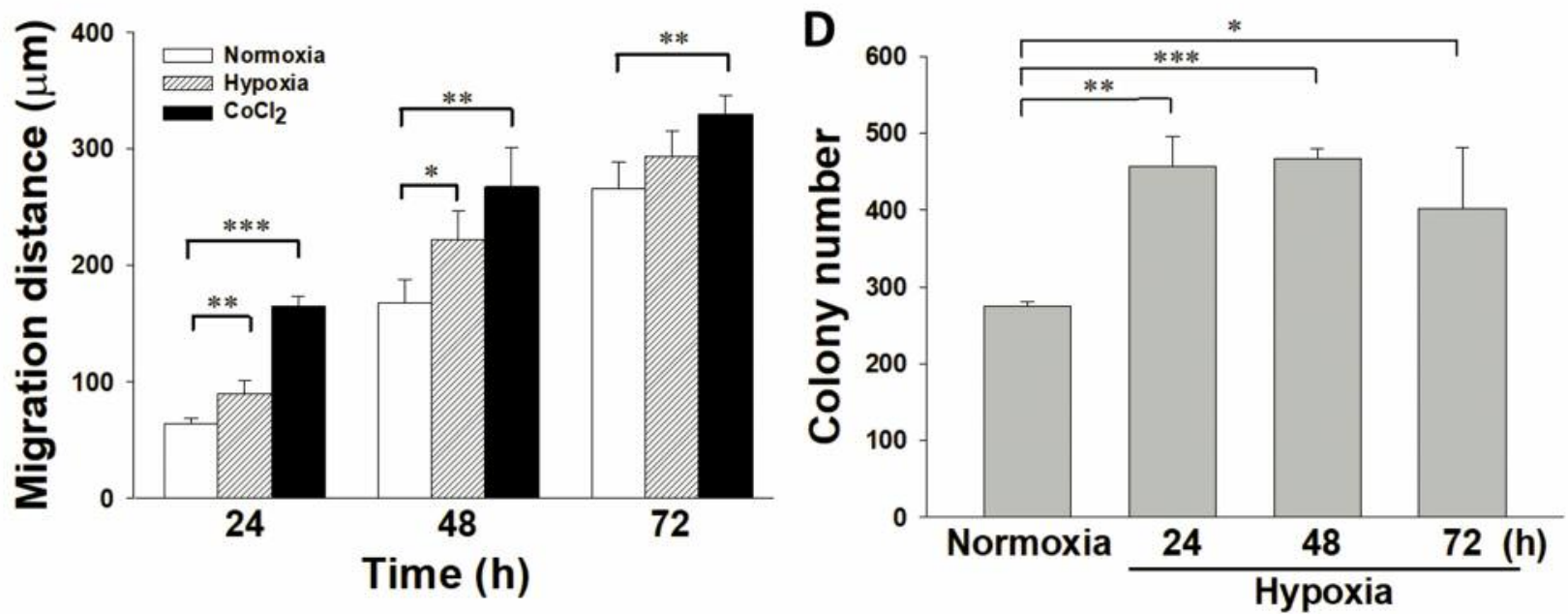

Figure 1. Hypoxia enhances cell migration and invasion of A549 human lung adenocarcinoma cells. A: A549 cells were subjected to wounding and then incubated under normoxia, hypoxia $\left(1 \% \mathrm{O}_{2}\right)$, or $100 \mu \mathrm{M}$ cobalt chloride $\left(\mathrm{CoCI}_{2}\right)$ for 24,48 , and 72 h. Changes in the wound-healing activity were visualized by phase-contrast microscopy at the indicated times. $B$ : The relative distance of the wounded area ( $\mu m$ ) is depicted. $C$ : The invasive ability of A549 cells was evaluated by transwell invasion assays under normoxia, hypoxia, or $100 \mu M \mathrm{CoCI}_{2}$ treatment for 24 h. Representative images show cells that had invaded through the transwell membrane. D: A soft-agar colony-formation assay was performed to evaluate the in vitro tumorigenicity of cells. A549 cells were incubated in normoxic or hypoxic conditions for 24, 48, and 72 h. Significantly different at *p<0.05, $* * p<0.01$, and $* * * p<0.001$ compared to the normoxic group.

Gelatin zymographic assay. Matrix metalloproteinase 2 (MMP2) and MMP9 activities were determined by a gelatin zymographic assay. In brief, the supernatant of A549 culture medium was collected and mixed with sample buffer dye $(250 \mathrm{mM}$ Tris- $\mathrm{HCl}$ $10 \%$ sodium dodecylsulfate (SDS), $0.5 \%$ bromophenol blue, and $50 \%$ glycerol) then electrophoresed in a $10 \%$ SDS polyacrylamide gel containing $0.1 \%$ gelatin. After electrophoresis, the gel was washed three times with $50 \mathrm{mM}$ Tris- $\mathrm{HCl}$ containing $2 \%$ Triton $\mathrm{X}-100$ and then washed three times with $50 \mathrm{mM}$ Tris-HCl. The gel was then incubated for an additional $18 \mathrm{~h}$ at $37^{\circ} \mathrm{C}$ for the enzymatic reactions of MMPs in reaction buffer $(50 \mathrm{mM}$ Tris- $\mathrm{HCl}, 0.2 \mathrm{M}$ $\mathrm{NaCl}, 5 \mathrm{mM} \mathrm{CaCl}_{2}, 0.02 \% \mathrm{NaN}_{3}, 2 \%$ Triton $\mathrm{X}-100$, and $1 \mathrm{M}$ $\mathrm{ZnCl}_{2}$ ). The gel was stained with Coomassie blue R-250 (Sigma) and then destained (methanol/acetic acid/water, 30/10/60). Images were then captured.
Luciferase reporter assay. A549 cells were transfected with the TOPFlash reporter plasmid containing eight copies of optimal (Super $8 \times$ TOPFlash) or mutant (Super $8 \times$ FOPFlash) transcription factor/Iymphoid enhancer-binding factor (TCF/LEF) binding sites upstream of luciferase. After $12 \mathrm{~h}$ of incubation, cells were treated with normoxia $\left(21 \% \mathrm{O}_{2}\right)$, hypoxia $\left(1 \% \mathrm{O}_{2}\right)$, or $100 \mu \mathrm{M}$ cobalt chloride for $24 \mathrm{~h}$. All cells were treated with $35 \mu \mathrm{l} / \mathrm{ml}$ luciferin (Promega, Madison, WI, USA) and then analyzed by luminometer (Sirius luminometer, Berthod, Pforzheim, Germany). The M50 Super $8 \times$ TOPFlash (Addgene plasmid \#12456) and M51 Super 8x FOPFlash (TOPFlash mutant) (Addgene plasmid \#12457) plasmids were gifts from Randall Moon (19).

Statistical analysis. All experiments were independently performed at least three times. Data are presented as the mean \pm standard error 
A

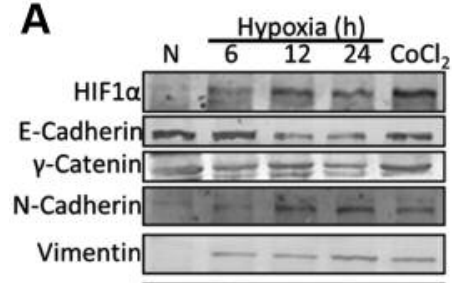

Actin $\longrightarrow$

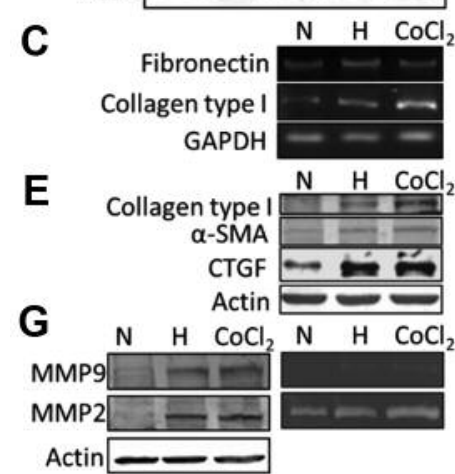

B
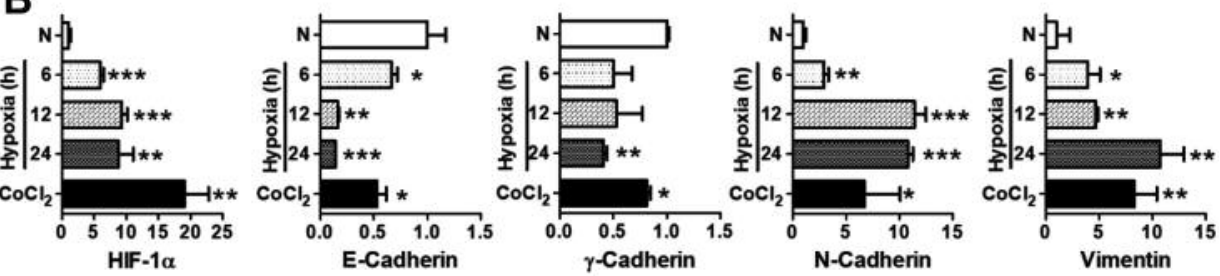

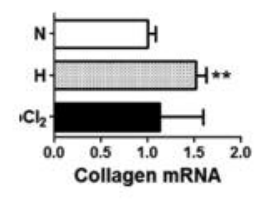

$F$
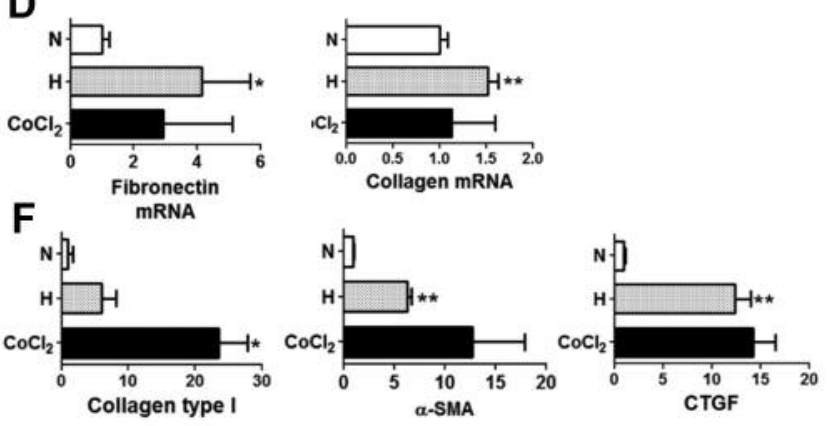

Figure 2. Effects of hypoxia on the expression of epithelial-to-mesenchymal transition (EMT)-related markers in A549 cells. A: A549 cells were cultured under normoxia $\left(21 \% \mathrm{O}_{2}, \mathrm{~N}\right)$, hypoxia $\left(1 \% \mathrm{O}_{2}, \mathrm{H}\right)$, or $100 \mu \mathrm{M}$ cobalt chloride $\left(\mathrm{CoCI}_{2}\right)$ treatment for 6,12 , and $24 \mathrm{~h}$. Expression of $\mathrm{N}$ cadherin and vimentin were up-regulated by hypoxic stimulation in parallel with down-regulation of the epithelial marker E-cadherin in a timedependent manner. B: Densitometric analysis of band intensities of each EMT-related marker shown in (A). C: Hypoxia-induced fibronectin and collagen type I mRNA expression was measured by a reverse-transcription polymerase chain reaction assay in A549 cells. D: Quantitative data of (C) are shown as the mean \pm SEM. E: Western blot analysis of $\alpha$-smooth muscle actin (SMA), a precursor form of collagen type I, and connective tissue growth factor (CTGF) expression in A549 cells under hypoxic stimulation. F: Densitometric analysis of band intensities shown in (E). G: Effects of hypoxia on matrix metalloproteinase (MMP) expression and activities in A549 cells. Representative zymography of conditioned media was collected from A549 cells which were cultured under the indicated conditions for $24 \mathrm{~h}$. The protein level and enzyme activity of MMPs were determined by western blot and zymographic analyses, respectively. Glyceraldehyde-3-phosphate dehydrogenase (GAPDH) and actin were used as the internal control. Significantly different at $* p<0.05$, **p<0.01, and $* * * p<0.001$ compared to the normoxic group.

of the mean (SEM). Statistical evaluation was performed using Student's $t$-test. $p$-Values of less than 0.05 were considered a statistically significant difference.

\section{Results}

Hypoxia enhanced cell migration and invasion of A549 human lung adenocarcinoma cells. To demonstrate that hypoxia is associated with the malignancy of lung cancer cells, cell migration, invasion, and tumorigenicity of hypoxia-treated A549 cells were analyzed through a wound-healing assay, invasion assay, and colony formation assay. After being treated with $1 \%$ $\mathrm{O}_{2}$ hypoxia or cobalt chloride-induced hypoxia, A549 cells showed augmented migratory activity (Figure 1A and B), invasive ability (Figure 1C), and cellular anchorage-independent growth (Figure 1D) within 24, 48, and $72 \mathrm{~h}$. These results suggest that hypoxia enhanced the malignancy of A549 cells.

Hypoxia promoted the EMT of lung cancer cells. Previous studies indicated that the EMT plays an essential role in cancer malignancy. To demonstrate whether the EMT is associated with enhancement of hypoxia-induced lung adenocarcinoma malignancy, expressions of EMT markers was detected by a western blot assay. As shown in Figure 2A and $\mathrm{B}$, protein expression of HIF1 $\alpha$ increased in hypoxiatreated A549 cells, as did that of $\mathrm{N}$-cadherin and vimentin. However, protein expression of E-cadherin and $\gamma$-catenin decreased. Switching of cadherin expression implies that the EMT might have occurred under hypoxic circumstances.

To assess the metastatic progression of hypoxia-treated A549 cells, changes in the cytoskeleton and extracellular matrix (ECM) were analyzed. Hypoxia induced fibronectin and collagen type I expression at the messenger (m)RNA level (Figure 2C and D). Increased expression levels of CTGF, collagen type I, and $\alpha$-SMA were also detected under hypoxic conditions (Figure $2 \mathrm{E}$ and $\mathrm{F}$ ).

Previous studies implicated that up-regulation of MMP2 and MMP9 expression in various types of human cancer might be correlated with advanced stage, invasion, and metastatic properties (20-22). To identify expression and enzymatic activity of MMPs in hypoxia-treated A549 cells, western blot 
A

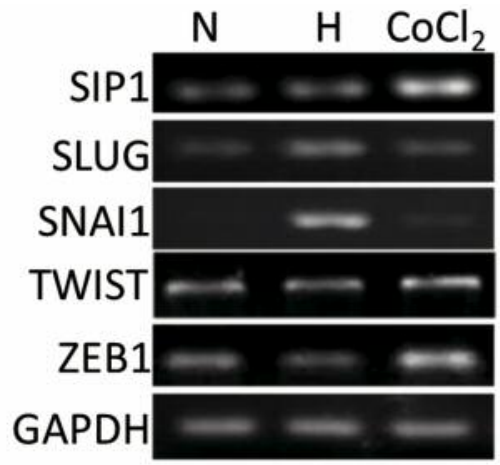

B

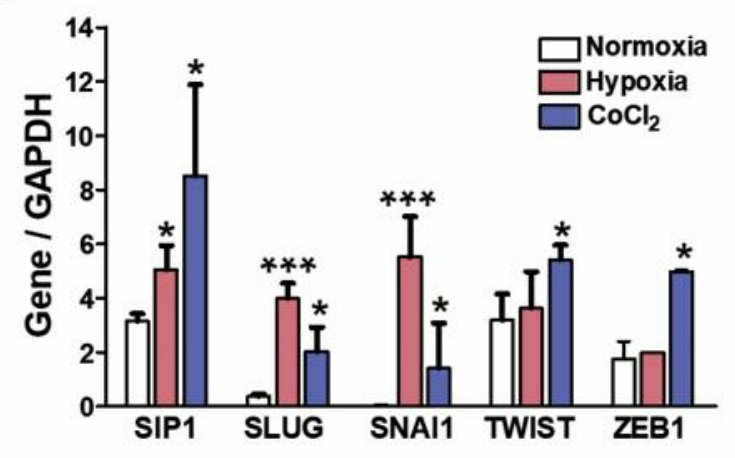

C

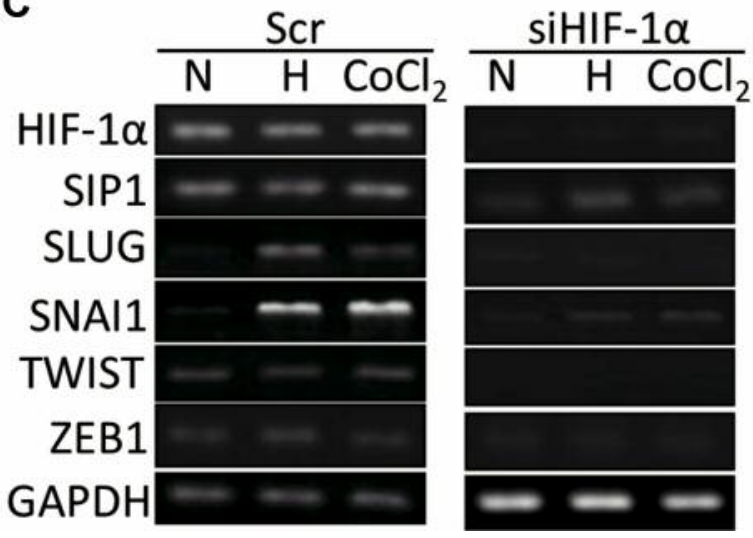

Figure 3. Hypoxia-inducible factor-1 $\alpha$ (HIF1 $\alpha$ ) mediates hypoxia-induced expression of snail family transcriptional repressors 1 (SNAII) and 2 (SLUG). A: Expression of epithelial-to-mesenchymal transition (EMT)related transcriptional factors SMAD interacting protein 1 (SIP1), SLUG, SNAI1, TWIST, and zinc finger E-box binding homeobox 1 (ZEB1) in normoxic $\left(21 \% \mathrm{O}_{2}, \mathrm{~N}\right)$ and hypoxic culture conditions $\left(1 \% \mathrm{O}_{2}, \mathrm{H}\right)$, and $100 \mathrm{mM}$ cobalt chloride $\left(\mathrm{CoCI}_{2}\right)$ mimic hypoxia for $24 \mathrm{~h}$ were measured by a reverse-transcription polymerase chain reaction assay $(R T-P C R) . B$ : Densitometric analysis of band intensities shown in (A). C: After transfection with HIFl $\alpha$ siRNA (siHIFl $\alpha$ ) or scrambled siRNA (Scr), A549 cells were subjected to hypoxia or $100 \mathrm{mM}$ cobalt chloride for $24 \mathrm{~h}$, and an RT-PCR assay was preformed to analyze expressions of genes at the mRNA level. Significantly different at $* p<0.05$ and $* * * p<0.001$ compared to the normoxic group. assay and gelatin zymographic analysis were carried out. In Figure $2 \mathrm{G}$, both hypoxic and cobalt chloride treatments increased MMP2 and MMP9 expression at the protein level. Hypoxic stimulation also up-regulated the enzymatic activity of MMP2 in A549 cells. These results suggest that hypoxic stimulation promoted the EMT in A549 cells.

HIF $1 \alpha$ is involved in hypoxia-mediated modulation of SLUG and SNAIL expressions. It was shown that transcriptional repression is one of the critical mechanisms for E-cadherin down-regulation during tumor progression $(11,23)$. Several transcriptional factors were described as repressors of Ecadherin expression, such as TWIST, SLUG, SNAI1, SMAD interacting protein 1 (SIP1), and zinc finger E-box binding homeobox 1 (ZEB1) (12, 23-26). To further investigate whether transcriptional repressors are involved in E-cadherin suppression under hypoxic stimulation, RT-PCR analysis was performed to detect expression of these repressors. Figure $3 \mathrm{~A}$ and $\mathrm{B}$ show that hypoxia significantly increased mRNA expression of SIP1, SLUG, and SNAI1, but not of TWIST or $Z E B 1$ in A549 cells $(p<0.001)$. To further confirm the role of HIF1 $\alpha$ in SIP1, SLUG, and SNAII mRNA expressions under hypoxic conditions, the expression of HIF1 $\alpha$ was knocked-down with HIF1 $\alpha$-specific small interfering (si)RNA. As shown in Figure 3C, transfection with HIF1 $\alpha$ siRNA dramatically inhibited hypoxia- and cobalt chlorideinduced SLUG and SNAII expression. These data suggest that HIF1 $\alpha$ mediates the induction of SLUG and SNAII mRNA under hypoxic conditions.

Hypoxia enhances nuclear accumulation and transcriptional activity of $\beta$-catenin. Previous studies indicated that Ecadherin recruits $\beta$-catenin to cell membranes and prevents nuclear translocation and transcriptional activity of $\beta$-catenin. Down-regulation of E-cadherin promotes $\beta$-catenin release and facilitates the EMT and transformation of cell phenotypes (27-29). Therefore, the next question was whether hypoxiainduced down-regulation of E-cadherin promotes nuclear translocation of $\beta$-catenin. Hypoxic stimulation reduced Ecadherin expression in the cytosol, while increased accumulation of $\beta$-catenin was found in nuclei (Figure 4A). To further verify whether hypoxia-induced nuclear translocation of $\beta$-catenin activates downstream gene expression, a $\beta$-catenin/TCF luciferase reporter assay was carried out. We transfected A549 cells with a wild-type $\beta$ catenin reporter plasmid and then stimulated them with hypoxia. Luciferase activity was elevated by both $1 \% \mathrm{O}_{2}$ hypoxia and cobalt chloride. On the contrary, luciferase activity did not change in cells transfected with the mutanttype $\beta$-catenin reporter plasmid (Figure 4B). Knockdown of $\beta$-catenin with siRNA reduced fibronectin, collagen type I, vimentin, $M M P 2$, and $M M P 9$ expression at the mRNA level under hypoxic stimulation (Figure 4C). Taken together, these 
A

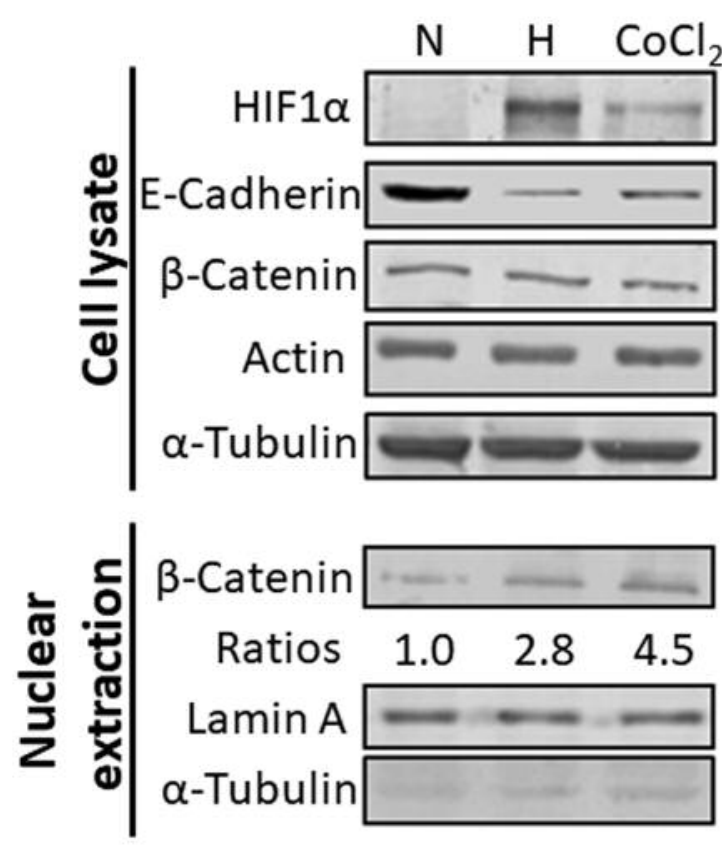

B

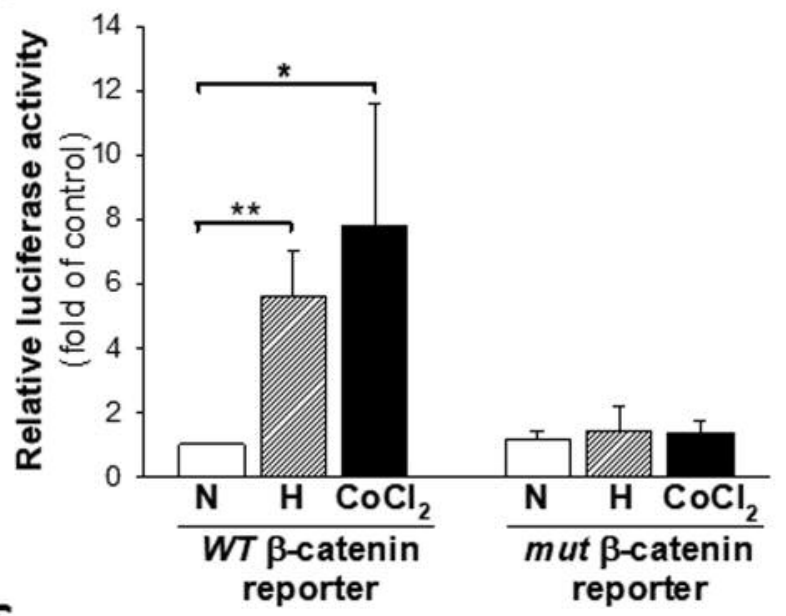

C

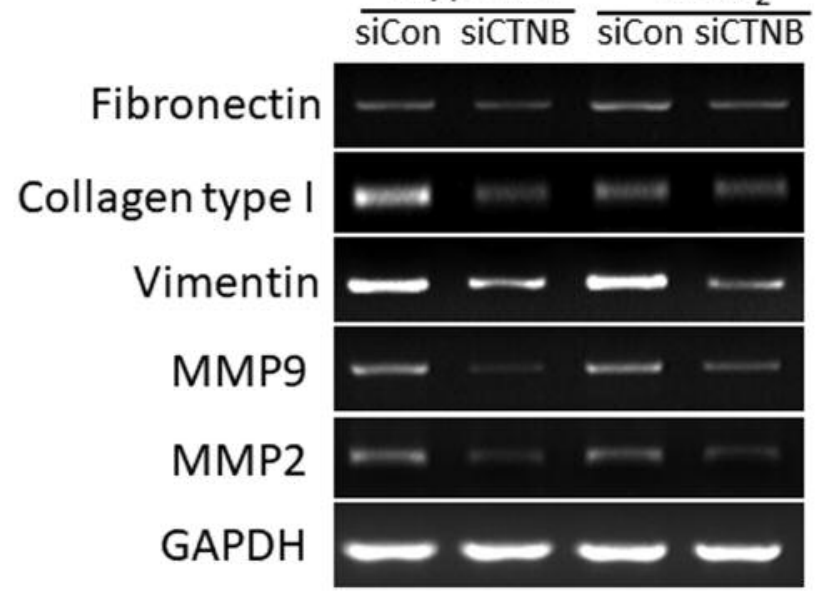

Figure 4. Hypoxia increases nuclear accumulation and transcriptional activity of $\beta$-catenin. A: Cytoplasmic and nuclear extracts were isolated from A549 cells under normoxia $\left(21 \% \mathrm{O}_{2}, \mathrm{~N}\right)$, hypoxia $\left(1 \% \mathrm{O}_{2}, \mathrm{H}\right)$, or $100 \mu \mathrm{M}$ cobalt chloride $\left(\mathrm{CoCI}_{2}\right)$ treatment for $24 \mathrm{~h}$. An immunoblot assay confirmed the increase in nuclear translocation of $\beta$-catenin in response to hypoxic stimulation. B: A luciferase reporter assay evaluated $\beta$-catenin-mediated transcriptional activation using a reporter containing either functional wild-type (WT $\beta$-catenin reporter) or mutated (mut $\beta$-catenin reporter) transcription factor (TCF) binding sites. A549 cells under hypoxic stimulation showed increased levels of $\beta$-catenin activity. $C$ : After transfection with $\beta$-catenin siRNA (siCTNB) or control siRNA (siCon), A549 cells were subjected to hypoxic conditions or $100 \mathrm{mM} \mathrm{CoCI}{ }_{2}$ treatment for 24 h, and a reverse-transcription polymerase chain reaction analysis of epithelial-to-mesenchymal transition-related genes was preformed. GAPDH: Glyceraldehyde-3-phosphate dehydrogenase; HIF1 $\alpha$ : hypoxia-inducible factor-1 $\alpha$; MMP: matrix metalloproteinase. Significantly different at $* p<0.05$ and ${ }^{* *} p<0.01$ compared to the normoxic group.

findings suggest that hypoxia-induced nuclear translocation of $\beta$-catenin and transactivation play crucial roles in the EMT processes of lung cancer.

\section{Discussion}

Hypoxia stimulates the EMT in lung cancer cells. Lung cancer is the leading cause of cancer deaths and is the second most commonly diagnosed cancer in both men and women $(1,2)$. Once lung cancer exhibits the metastatic phenotype, the prognosis and survival rate of patients greatly worsen (4).
Preventing and overcoming lung cancer metastasis are vital issues for lung cancer therapy.

The work presented here shows that hypoxia promoted lung cancer metastasis through nuclear accumulation of $\beta$ catenin and thus induced the EMT. In the hypoxic microenvironment of lung cancer cells, HIF1 $\alpha$ induced expression of the transcriptional suppressors, SNAII and $S L U G$, and then down-regulated E-cadherin expression. Lower E-cadherin expression led to $\beta$-catenin translocation from cell membranes to nuclei and subsequently enhanced expression of MMP2, MMP9, vimentin, fibronectin, and 


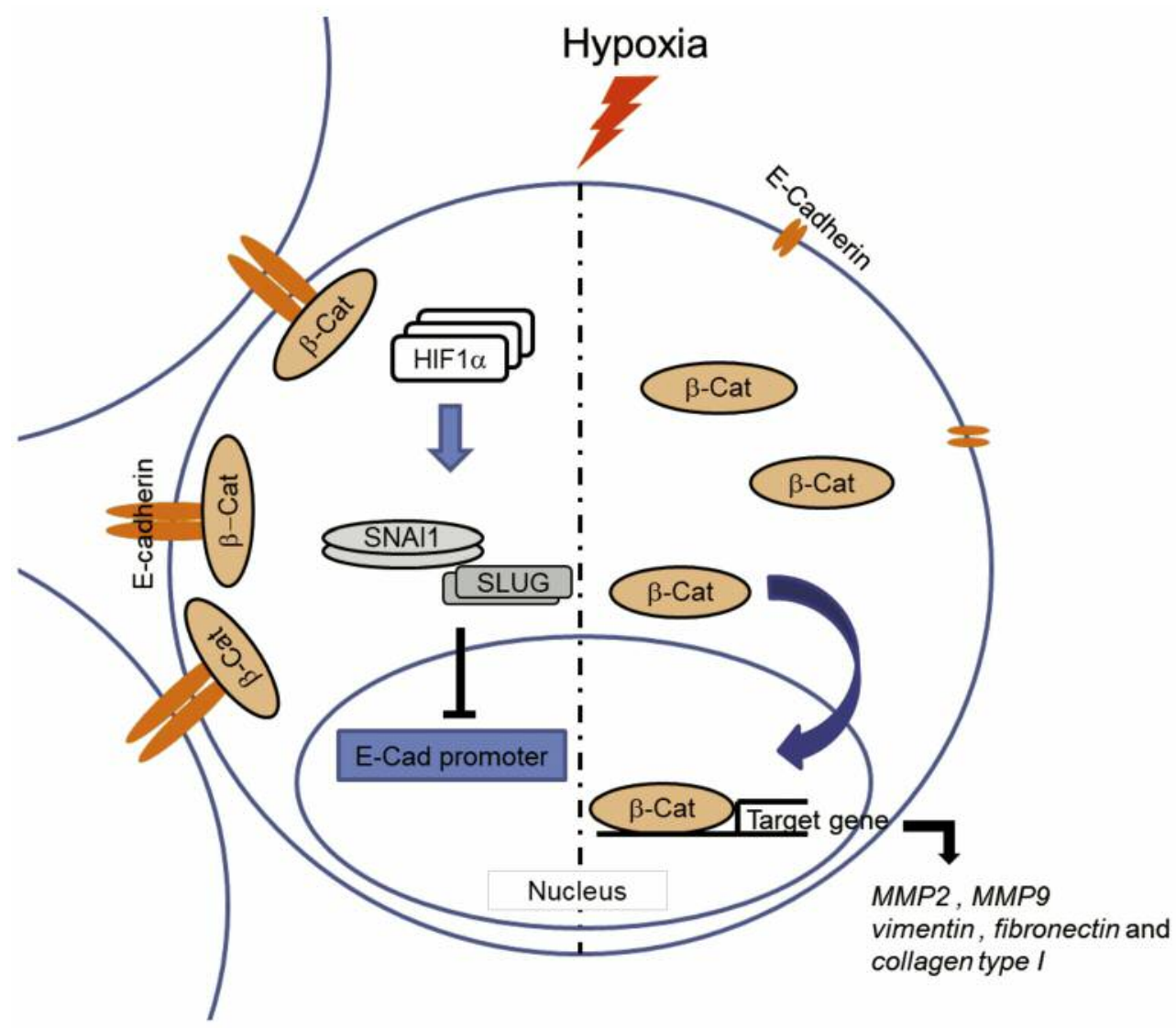

Figure 5. A proposed model describing the effects of hypoxia on lung cancer metastasis. In the unfavorable hypoxic microenvironment of the primary tumor (left hand side), hypoxia-inducible factor-1 $\alpha$ (HIF1 $\alpha$ ) induces expression of snail family transcriptional repressors 1 (SNAI1) and 2 (SLUG), then inhibits E-cadherin transcription. Cells were more invasive and had reduced cell-cell adhesion. After hypoxia stimulation, lower E-cadherin expression led to nuclear localization of $\beta$-catenin (right hand side). These cells exhibited less cell-cell adhesion and greater invasiveness.

collagen type I. Therefore, hypoxic lung cancer cells exhibit less cell-cell adhesion and greater invasiveness (Figure 5).

Hypoxia and cancer progression. Hypoxia is a common condition of the tumor microenvironment. Emerging data suggest that a hypoxic microenvironment might play pivotal roles in progression of solid tumors (6). Due to restricted blood flow, the oxygen consumption rate of cancer cells might override the oxygen supply from the vessels and result in an imbalance between supply and consumption leading to a hypoxic tumor microenvironment (5). Previous studies suggested that hypoxia might induce long-term silencing of breast cancer 1 (BRCAl) promoter, and then induce breast cancer genome instability and tumor progression (30). In glioblastoma tissues, hypoxia increased $O^{6}$-methylguanineDNA methyltransferase (MGMT) expression and thereby suppressed tumor sensitivity to temozolomide (31). Research has suggested that tumor hypoxia limits patient survival by inducing tumor genetic instability, increasing therapeutic resistance, and promoting the metastatic ability of tumors (32).

In the hypoxic tumor microenvironment, expression of HIFs increased and that of downstream pathway members, including pluripotency-associated transcription factors [octamer-binding transcription factor 3/4, NANOG, and sex determining region Y-box 2], angiogenic factors (vascular endothelial growth factor), and EMT program-associated molecules (C-X-C chemokine receptor type 4, SNAI1, and TWIST) (33), was activated. These respectively promote tumor self-renewal, tumor vessel proliferation, and tumorinvasive capabilities (33).

HIFla induces EMT. Previous studies suggested that hypoxia induces tumor cells to undergo EMT; however, the mechanisms underlying this are still elusive. It was shown that hypoxic induction of dimerization of HIF $1 \alpha$ and HIF $1 \beta$ in nuclei is important for tumor metastasis. The HIF $1 \alpha$ and HIF $1 \beta$ heterodimer binds to the hypoxia-response element (HRE) and transactivates EMT-related genes, thereby 
promoting the invasive ability of breast cancer and head and neck cancer $(34,35)$. Furthermore, NOTCH signaling might be essential for hypoxia-induced EMT in tumor tissues. Sahlgren et al. (36) and Chen et al. (10) suggested that NOTCH signaling mediates HIF1 $\alpha$ recruitment and increases expression of SLUG and SNAI1, thereby increasing the migration and invasion of cancer cells $(10,36)$. In this study, we demonstrated that hypoxia stabilized HIF1 $\alpha$ and stimulated cell migration, invasion, and anchorageindependent growth of A549 cells.

On the other hand, hypoxia might promote the EMT in pulmonary cells via releasing cytokines, such as epithelial growth factor (EGF), insulin-like growth factor-1 (IGF1), fibroblast growth factor (FGF), hepatocyte growth factor (HGF), transforming growth factor $\beta$ (TGF $\beta$ ), and endothelin1 (37-42). In 2016, Wang et al. suggested that hypoxia enhances TGF $\beta$ - and IL10-containing exosomes, and thus promotes the migratory ability of lung cancer cells (43). Matsuoka et al. indicated that hypoxia might stimulate the EMT via autocrine TGF $\beta$ and TGF $\beta$ receptor signaling axis in gastric cancer cells (15). Hypoxia-induced cytokine release activates various signaling pathways, such as $\mathrm{NOTCH}$ signaling, the EGF receptor pathway, and the WNT/ $\beta$-catenin signaling pathway. This might further initiate tumor malignancies including invasion, migration, and metastasis.

$\beta$-Catenin crosstalk with HIFl $\alpha$ and the EMT. $\beta$-Catenin plays a vital role in hypoxia-induced EMT. The results of the present study suggest that HIF1 $\alpha$ promotes lung cancer metastasis through accumulation of nuclear $\beta$-catenin and thus induces the EMT. Consistent with this, a previous study also reported that crosstalk between $\beta$-catenin and HIF1 $\alpha$ promoted colon cancer cell proliferation and adaptation to hypoxia (8). Xi et al. also demonstrated that phosphorylated $\beta$-catenin, as a critical cofactor, specifically complexed with HIF $1 \alpha$ and promoted transcription of EMT genes (44). On the other hand, the phosphatase and tensin homolog (PTEN) might participate in hypoxia-induced accumulation of $\beta$ catenin. Recent studies suggested that the hypoxia-induced EMT phenotype was negatively regulated by PTEN $(7,45)$. Kohon et al. implied that hypoxia suppressed PTEN activity and thus induced $\beta$-catenin translocation into the cytoplasm and nuclei (7). Knockdown of PTEN resulted in nuclear accumulation of $\beta$-catenin and EMT induction in colon cancer cells (45). Overall, $\beta$-catenin appears to be an important tumorigenic factor in cancer cells in response to a hypoxic microenvironment. Our findings provide a potential mechanism for the contribution of hypoxia to lung carcinoma metastasis.

Prognostic markers and potential therapeutic interventions. Metastasis in lung cancer is a multifaceted process. It was shown that HIF1 $\alpha$ expression is a significant prognostic predictor for patients with non-small cell lung cancer (46). Recently, several meta-analytical studies revealed that HIF1 $\alpha$ expression may be a prognostic biomarker and a potential therapeutic target for lung cancer $(9,47)$. Consistent with clinical and meta-analytical studies, the present study also indicated a potential mechanism of HIF $1 \alpha$ in promoting lung cancer malignancy.

Inhibition of cancer metastasis is still a vital issue in lung cancer therapy. Suppressing hypoxia-induced cancer metastasis might be a potential therapeutic strategy $(13,14)$. An HIF1 $\alpha$-targeted therapeutic agent prolonged survival and sensitized to a radiotherapeutic response in preclinical brain tumor research (48). Emodin down-regulated the $\beta$-catenin and protein kinase B (AKT) pathways and thus inhibited TWIST1-induced EMT in head and neck squamous cell carcinoma cells (49). While further comprehensive research is still needed, the present study revealed a mechanism underlying hypoxia-induced lung cancer metastasis, that might provide a potential therapeutic target for development of anticancer agents in the future.

\section{Conflicts of Interest}

The Authors confirm that there are no known conflicts of interest associated with this publication.

\section{References}

1 Siegel RL, Miller KD and Jemal A: Cancer statistics, 2018. CA Cancer J Clin 68(1): 7-30, 2018.

2 American Cancer Society. Cancer Facts \& Figures 2018, available at https://www.cancer.org/content/dam/cancer-org/research/cancerfacts-and-statistics/annual-cancer-facts-and-figures/2018/cancerfacts-and-figures-2018.pdf accessed 22/10/2018.

3 Guan X: Cancer metastases: Challenges and opportunities. Acta Pharm Sin B 5(5): 402-418, 2015.

4 Riihimaki M, Hemminki A, Fallah M, Thomsen H, Sundquist K, Sundquist $\mathrm{J}$ and Hemminki $\mathrm{K}$ : Metastatic sites and survival in lung cancer. Lung Cancer 86(1): 78-84, 2014.

5 Vaupel P and Mayer A: Hypoxia in cancer: Significance and impact on clinical outcome. Cancer Metastasis Rev 26(2): 225239, 2007.

6 Gilkes DM, Semenza GL and Wirtz D: Hypoxia and the extracellular matrix: Drivers of tumour metastasis. Nat Rev Cancer 14(6): 430-439, 2014

7 Kohnoh T, Hashimoto N, Ando A, Sakamoto K, Miyazaki S, Aoyama D, Kusunose M, Kimura M, Omote N, Imaizumi K, Kawabe T and Hasegawa Y: Hypoxia-induced modulation of PTEN activity and emt phenotypes in lung cancers. Cancer Cell Int 16: 33, 2016.

8 Kaidi A, Williams AC and Paraskeva C: Interaction between beta-catenin and HIF-1 promotes cellular adaptation to hypoxia. Nat Cell Biol 9(2): 210-217, 2007.

9 Ren W, Mi D, Yang K, Cao N, Tian J, Li Z and Ma B: The expression of hypoxia-inducible factor-1alpha and its clinical significance in lung cancer: A systematic review and metaanalysis. Swiss Med Wkly 143: w13855, 2013. 
10 Chen J, Imanaka N and Griffin JD: Hypoxia potentiates NOTCH signaling in breast cancer leading to decreased E-cadherin expression and increased cell migration and invasion. $\mathrm{Br} \mathrm{J}$ Cancer 102(2): 351-360, 2010.

11 Adhikary A, Chakraborty S, Mazumdar M, Ghosh S, Mukherjee S, Manna A, Mohanty S, Nakka KK, Joshi S, De A, Chattopadhyay S, Sa G and Das T: Inhibition of epithelial to mesenchymal transition by E-cadherin up-regulation via repression of SLUG transcription and inhibition of E-cadherin degradation: Dual role of scaffold/matrix attachment regionbinding protein 1 (SMAR1) in breast cancer cells. J Biol Chem 289(37): 25431-25444, 2014.

12 Elloul S, Elstrand MB, Nesland JM, Trope CG, Kvalheim G, Goldberg I, Reich R and Davidson B: SNAIL, SLUG, and SMAD-interacting protein 1 as novel parameters of disease aggressiveness in metastatic ovarian and breast carcinoma. Cancer 103(8): 1631-1643, 2005.

13 Wigerup C, Pahlman S and Bexell D: Therapeutic targeting of hypoxia and hypoxia-inducible factors in cancer. Pharmacol Ther 164: 152-169, 2016.

14 Wilson WR and Hay MP: Targeting hypoxia in cancer therapy. Nat Rev Cancer 11(6): 393-410, 2011.

15 Matsuoka J, Yashiro M, Doi Y, Fuyuhiro Y, Kato Y, Shinto O, Noda S, Kashiwagi S, Aomatsu N, Hirakawa T, Hasegawa T, Shimizu K, Shimizu T, Miwa A, Yamada N, Sawada T and Hirakawa K: Hypoxia stimulates the EMT of gastric cancer cells through autocrine TGF beta signaling. PLoS One 8(5): e62310, 2013.

16 Murakami K, Wu Y, Imaizumi T, Aoki Y, Liu Q, Yan X, Seino $\mathrm{H}$, Yoshizawa T, Morohashi S, Kato Y and Kijima H: DEC1 promotes hypoxia-induced epithelial-mesenchymal transition (EMT) in human hepatocellular carcinoma cells. Biomed Res 38(4): 221-227, 2017.

17 Liu KH, Yang ST, Lin YK, Lin JW, Lee YH, Wang JY, Hu CJ, Lin EY, Chen SM, Then CK and Shen SC: Fluoxetine, an antidepressant, suppresses glioblastoma by evoking AMPARmediated calcium-dependent apoptosis. Oncotarget 6(7): 50885101,2015

18 Then CK, Liu KH, Liao MH, Chung KH, Wang JY and Shen SC: Antidepressants, sertraline and paroxetine, increase calcium influx and induce mitochondrial damage-mediated apoptosis of astrocytes. Oncotarget 8(70): 115490-115502, 2017.

19 Veeman MT, Slusarski DC, Kaykas A, Louie SH and Moon RT: Zebrafish prickle, a modulator of noncanonical WNT/FZ signaling, regulates gastrulation movements. Curr Biol 13(8): 680-685, 2003.

20 Lokeshwar BL, Selzer MG, Block NL and Gunja-Smith Z: Secretion of matrix metalloproteinases and their inhibitors (tissue inhibitor of metalloproteinases) by human prostate in explant cultures: Reduced tissue inhibitor of metalloproteinase secretion by malignant tissues. Cancer Res 53(19): 4493-4498, 1993.

21 Rundhaug JE: Matrix metalloproteinases, angiogenesis, and cancer: Commentary re: A. C. Lockhart et al., reduction of wound angiogenesis in patients treated with bms-275291, a broad spectrum matrix metalloproteinase inhibitor. Clin. Cancer Res., 9: 00-00, 2003. Clin Cancer Res 9(2): 551-554, 2003.

22 Tester AM, Ruangpanit N, Anderson RL and Thompson EW: MMP-9 secretion and MMP-2 activation distinguish invasive and metastatic sublines of a mouse mammary carcinoma system showing epithelial\&mesenchymal transition traits. Clin Exp Metastasis 18(7): 553-560, 2000.
23 Bolos V, Peinado H, Perez-Moreno MA, Fraga MF, Esteller M and Cano A: The transcription factor SLUG represses E-cadherin expression and induces epithelial to mesenchymal transitions: A comparison with SNAIL and E47 repressors. J Cell Sci 116(Pt 3): 499-511, 2003.

24 von Burstin J, Eser S, Paul MC, Seidler B, Brandl M, Messer M, von Werder A, Schmidt A, Mages J, Pagel P, Schnieke A, Schmid RM, Schneider G and Saur D: E-Cadherin regulates metastasis of pancreatic cancer in vivo and is suppressed by a SNAIL/HDAC1/HDAC2 repressor complex. Gastroenterology 137(1): 361-371, 371 e361-365, 2009.

25 Yoshida R, Morita M, Shoji F, Nakashima Y, Miura N, Yoshinaga K, Koga T, Tokunaga E, Saeki H, Oki E, Oda Y and Maehara Y: Clinical significance of SIP1 and E-cadherin in patients with esophageal squamous cell carcinoma. Ann Surg Oncol 22(8): 2608-2614, 2015.

26 Qin Y, Tang B, Hu CJ, Xiao YF, Xie R, Yong X, Wu YY, Dong $\mathrm{H}$ and Yang SM: An hTERT/ZEB1 complex directly regulates E-cadherin to promote epithelial-to-mesenchymal transition (EMT) in colorectal cancer. Oncotarget 7(1): 351-361, 2016.

27 Orsulic S, Huber O, Aberle H, Arnold S and Kemler R: ECadherin binding prevents beta-catenin nuclear localization and beta-catenin/LEF-1-mediated transactivation. J Cell Sci 112 (Pt 8): 1237-1245, 1999.

28 Su YJ, Chang YW, Lin WH, Liang CL and Lee JL: An aberrant nuclear localization of E-cadherin is a potent inhibitor of WNT/beta-catenin-elicited promotion of the cancer stem cell phenotype. Oncogenesis 4: e157, 2015.

29 Tian X, Liu Z, Niu B, Zhang J, Tan TK, Lee SR, Zhao Y, Harris DC and Zheng G: E-Cadherin/beta-catenin complex and the epithelial barrier. J Biomed Biotechnol 2011: 567305, 2011.

$30 \mathrm{Lu} \mathrm{Y,} \mathrm{Chu} \mathrm{A,} \mathrm{Turker} \mathrm{MS} \mathrm{and} \mathrm{Glazer} \mathrm{PM:} \mathrm{Hypoxia-induced}$ epigenetic regulation and silencing of the BRCA1 promoter. Mol Cell Biol 31(16): 3339-3350, 2011.

31 Pistollato F, Abbadi S, Rampazzo E, Persano L, Della Puppa A, Frasson C, Sarto E, Scienza R, D'Avella D and Basso G: Intratumoral hypoxic gradient drives stem cells distribution and MGMT expression in glioblastoma. Stem Cells 28(5): 851-862, 2010.

32 Luoto KR, Kumareswaran R and Bristow RG: Tumor hypoxia as a driving force in genetic instability. Genome Integr 4(1): 5, 2013.

33 Mimeault $\mathrm{M}$ and Batra SK: Hypoxia-inducing factors as master regulators of stemness properties and altered metabolism of cancer- and metastasis-initiating cells. J Cell Mol Med 17(1): 30-54, 2013.

34 Ryu MH, Park HM, Chung J, Lee CH and Park HR: Hypoxiainducible factor-1alpha mediates oral squamous cell carcinoma invasion via upregulation of alpha5 integrin and fibronectin. Biochem Biophys Res Commun 393(1): 11-15, 2010.

35 Yang MH, Wu MZ, Chiou SH, Chen PM, Chang SY, Liu CJ, Teng SC and Wu KJ: Direct regulation of TWIST by HIF-1alpha promotes metastasis. Nat Cell Biol 10(3): 295-305, 2008.

36 Sahlgren C, Gustafsson MV, Jin S, Poellinger L and Lendahl U: NOTCH signaling mediates hypoxia-induced tumor cell migration and invasion. Proc Natl Acad Sci USA 105(17): 6392-6397, 2008.

37 Willis BC, Liebler JM, Luby-Phelps K, Nicholson AG, Crandall $\mathrm{ED}$, du Bois RM and Borok $\mathrm{Z}$ : Induction of epitheliamesenchymal transition in alveolar epithelial cells by transforming growth factor-beta1: Potential role in idiopathic pulmonary fibrosis. Am J Pathol 166(5): 1321-1332, 2005. 
$38 \mathrm{Wu}$ Z, Yang L, Cai L, Zhang M, Cheng X, Yang X and Xu J: Detection of epithelial to mesenchymal transition in airways of a bleomycin induced pulmonary fibrosis model derived from an alpha-smooth muscle actin-CRE transgenic mouse. Respir Res 8: $1,2007$.

39 Jain R, Shaul PW, Borok Z and Willis BC: Endothelin-1 induces alveolar epithelial-mesenchymal transition through endothelin type a receptor-mediated production of TGF-beta1. Am J Respir Cell Mol Biol 37(1): 38-47, 2007.

40 Smith A, Teknos TN and Pan Q: Epithelial to mesenchymal transition in head and neck squamous cell carcinoma. Oral Oncol 49(4): 287-292, 2013.

41 Hung CM, Kuo DH, Chou CH, Su YC, Ho CT and Way TD: Osthole suppresses hepatocyte growth factor (Hgf)-induced epithelial-mesenchymal transition via repression of the cMET/AKT/MTOR pathway in human breast cancer cells. J Agric Food Chem 59(17): 9683-9690, 2011.

42 Miyazono K, Ehata S and Koinuma D: Tumor-promoting functions of transforming growth factor-beta in progression of cancer. Ups J Med Sci 117(2): 143-152, 2012.

43 Wang Y, Yi J, Chen X, Zhang Y, Xu M and Yang Z: The regulation of cancer cell migration by lung cancer cell-derived exosomes through TGF-beta and IL-10. Oncol Lett 11(2): 15271530, 2016.

44 Xi Y, Wei Y, Sennino B, Ulsamer A, Kwan I, Brumwell AN, Tan K, Aghi MK, McDonald DM, Jablons DM and Chapman HA: Identification of py654-beta-catenin as a critical co-factor in hypoxia-inducible factor-1alpha signaling and tumor responses to hypoxia. Oncogene 32(42): 5048-5057, 2013.
45 Bowen KA, Doan HQ, Zhou BP, Wang Q, Zhou Y, Rychahou PG and Evers BM: PTEN loss induces epithelial-mesenchymal transition in human colon cancer cells. Anticancer Res 29(11): 4439-4449, 2009.

46 Hung JJ, Yang MH, Hsu HS, Hsu WH, Liu JS and Wu KJ: Prognostic significance of hypoxia-inducible factor-1alpha, TWIST1 and SNAIL expression in resectable non-small cell lung cancer. Thorax 64(12): 1082-1089, 2009.

47 Yang SL, Ren QG, Wen L and Hu JL: Clinicopathological and prognostic significance of hypoxia-inducible factor-1 alpha in lung cancer: A systematic review with meta-analysis. J Huazhong Univ Sci Technolog Med Sci 36(3): 321-327, 2016.

48 Mangraviti A, Raghavan T, Volpin F, Skuli N, Gullotti D, Zhou J, Asnaghi L, Sankey E, Liu A, Wang Y, Lee DH, Gorelick N, Serra R, Peters M, Schriefer D, Delaspre F, Rodriguez FJ, Eberhart CG, Brem H, Olivi A and Tyler B: HIF-1alpha- targeting acriflavine provides long term survival and radiological tumor response in brain cancer therapy. Sci Rep 7(1): 14978, 2017.

49 Way TD, Huang JT, Chou CH, Huang $\mathrm{CH}$, Yang $\mathrm{MH}$ and Ho CT: Emodin represses TWIST1-induced epithelial-mesenchymal transitions in head and neck squamous cell carcinoma cells by inhibiting the beta-catenin and AKT pathways. Eur J Cancer 50(2): 366-378, 2014.
Received October 8, 2018

Revised October 22, 2018

Accepted October 23, 2018 